\title{
Location of rRNA Transcription to the Nucleolar Components: Disappearance of the Fibrillar Centers in Nucleoli of Regenerating Rat Hepatocytes
}

\author{
Lorenzo Montanaro ${ }^{1}$, Marzia Govoni ${ }^{1}$, Catia Orrico², Davide Treré1, and Massimo Derenzini2 ${ }^{*}$ \\ ${ }^{1}$ Department of Experimental Pathology, University of Bologna, Via S. Giacomo 14, 40126 Bologna, Italy, \\ ${ }^{2}$ Clinical Department of Radiological and Histocytopathological Sciences, Policlinico S. Orsola, Via \\ Massarenti 9, 40138 Bologna, Italy
}

\begin{abstract}
$A B S T R A C T$. The precise location of rDNA transcription to the components of mammalian cell nucleolus is still debated. This was due to the fact that all the molecules necessary for rRNA synthesis are located in two of the three components, the fibrillar centers (FCs) and the dense fibrillar component (DFC), which together with the granular component (GC) are considered to be constantly present in mammalian cell nucleoli. In the present study we demonstrated that in nucleoli of many regenerating rat hepatocytes at $\mathbf{1 5} \mathbf{h}$ after partial hepatectomy the FCs were no longer present, only the DFC and the GC being detected. At this time of regeneration the rRNA transcriptional activity was three fold that of resting hepatocytes, while the synthesis of DNA was not yet significantly increased, indicating that these nucleolar changes were due to the rRNA synthesis up-regulation. The DFC appeared to be organized in numerous, small, roundish tufts of fibrils. The silver staining procedure for AgNOR proteins, which are associated with the ribosomal genes, selectively and homogeneously stained these fibrillar tufts. Immuno-gold visualization of the Upstream Binding Factor (UBF), which is associated with the promoter region and the transcribed portion of the rRNA 45S gene, demonstrated that UBF was selectively located in the fibrillar tufts. We concluded that in proliferating rat hepatocytes the increased synthesis of rRNA induced an activation of the rRNA transcription machinery located in the fibrillar centers which, by becoming associated with the ribonucleoprotein transcripts, assumed the morphological pattern of the DFC.
\end{abstract}

Key words: mammalian cell nucleolus/rDNA transcription/fibrillar center/dense fibrillar component/electron microscopy

\section{Introduction}

The nucleolus is a well defined domain in interphase nucleus of eukaryotic cells, where ribosomal gene are located and ribosome biogenesis occurs (Hadjiolov, 1985). Ultrastructural studies have shown that in mammalian cell nucleoli, a part from intranucleolar chromatin, three main components are constantly present: the fibrillar centers (FCs), which are light electron-opaque, roundish structures composed by thin, loosely distributed fibrils, the dense fibrillar component (DFC) constituted by tightly packed fibrils, which surround and are intimately associated to the fibrillar centers, and the granular component (GC), constituted by granules with a diameter of 15-20 nm, which embeds both fibrillar components (Hadjiolov, 1985). There is evidence that ribosomal

\footnotetext{
*To whom correspondence should be addressed: Massimo Derenzini, Clinical Department of Radiological and Histocytopathological Sciences, Policlinico S. Orsola, Via Massarenti 9, 40138 Bologna, Italy.

Tel: ++39-51-6363607/302874, Fax: ++39-51-306861

E-mail: massimo.derenzini@unibo.it
}

genes in an extended, ready-to-be-transcribed configuration are mainly located in the FCs and, in part, within the DFC (Derenzini et al., 1993a; Mosgoeller et al., 1993) and all the substances necessary for rRNA transcription are present both in the FCs and in the DFC (Derenzini et al., 2006). In the DFC nascent pre-rRNA molecules undergo to early processing and maturation reactions which continue in the GC where pre-ribosomes in an advanced stage of maturation are located (Scheer and Hock, 1999). Regarding the site of transcription the debate is still open on where it precisely takes place, whether within the FCs or at the border of the FC or within the DFC (Huang, 2002). Interestingly, this was not the case for nucleoli of lower eukaryotes, in which the tripartite organization is not present, lacking structures that can be referred to FCs (Thiry and Lafontaine, 2005). In fact, there is a general consensus on the fact that in cell nucleoli of lower eukaryotes the rRNA transcription is located to the DFC.

Even though the presence of the FCs has been up to now considered a constant characteristic of mammalian nucleoli 
it is also well known that their relative distribution within the nucleolar body is highly variable from cell to cell and within the same type of cell according to its rRNA transcriptional activity. In resting cells, such as human circulating lymphocytes, stimulation of proliferation by phytohemagglutinin induces dramatic changes in the nucleolar morphology which varies from the very simple ring-shape organization to a well developed nucleolonema organization of the nucleolar components, upon the progressive increase of rRNA transcription (Derenzini et al., 1987; Hozak et al., 1989; Ochs and Smetana, 1989). The solitary, very large FC, which characterizes the resting lymphocytes appear to progressively fragmentize in numerous FCs of progressively smaller size surrounded by a rim of DFC. It has been proposed that these changes are the consequence of the fact that the ribosomal genes which are, in the inner portion of the FCs, transcriptionally inactive and nevertheless in a ready-to-be-transcribed configuration, become progressively active in synthesizing the rRNA precursors. These rRNA precursors, by steric hindrance, progressively separate the still inactive ribosomal genes located in the FCs, thus giving rise to progressively smaller FCs (Derenzini et al., 2006). The observation that the stimulation of rRNA synthesis is inversely related to the size of FCs might allow to suggest that when activation of ribosome genes occurs, they, by becoming covered by the rRNA transcripts, constitute a portion of the DFC thus indicating this nucleolar component as the site of transcription. However, only the complete disappearance of the FCs upon stimulation of rRNA transcription could clearly demonstrate the validity of a similar hypothesis, but up to now this has been never observed to occur in mammalian cell nucleoli. With the aim to verify this hypothesis, the changes of the distribution of the nucleolar components have been investigated in rat hepatocytes, which are normally characterized by an intense ribosome biogenesis, and in which rRNA transcription was further stimulated by partial hepatectomy.

\section{Materials and Methods}

\section{Animals}

Rats of the Wistar strain, weighing 100-120 g, were used. Partial hepatectomy was performed according to the method of Higgins and Anderson (1931) under ether anesthesia. Sham-operated rats were used as controls.

\section{Evaluation of DNA synthesis}

The synthesis of DNA was evaluated in partially hepatectomized rats at 15 and $24 \mathrm{~h}$ after partial hepatectomy and in sham-operated rats according to Pession et al. (1991) after $\left[{ }^{3} \mathrm{H}\right]$ methyl-thymidine (Amersham International, UK) injection $(10 \mu \mathrm{C} 1 / 100 \mathrm{~g}$ b/w; sp act $25 \mathrm{Ci} / \mathrm{mmol}$ ). Three rats were used for each time of regeneration.
Animals were killed 30 min after injection. DNA was extracted in $7 \%$ perchloric acid at $70^{\circ} \mathrm{C}$ for $15 \mathrm{~min}$. The radioactivity was measured after the addition of scintillation fluid (Ready Solv. Beckman Instruments, Fullerton, Calif., USA).

\section{Evaluation of $r R N A$ transcriptional activity}

Fragments of liver samples from three partially hepatectomized rats at $15 \mathrm{~h}$ after partial hepatectomy and from three sham-operated rats were homogenized in $2.20 \mathrm{M}$ sucrose containing $0.01 \mathrm{M}$ Tris$\mathrm{HCl}(\mathrm{pH} 7.4)$ and $0.01 \mathrm{M} \mathrm{MgCl}_{2}$, then centrifuged at $25000 \mathrm{~g}$ for $1 \mathrm{~h}$. Pellets were suspended in $0.25 \mathrm{M}$ sucrose containing $0.01 \mathrm{M}$ Tris- $\mathrm{HCl}(\mathrm{pH} 7.4), 0.01 \mathrm{M} \mathrm{MgCl}_{2}$, and $0.1 \%$ Triton $\mathrm{X}-100$, incubated for $10 \mathrm{~min}$ at $4^{\circ} \mathrm{C}$, and centrifuged at $1000 \mathrm{~g}$ for $10 \mathrm{~min}$. Nuclear pellets were washed twice with $0.25 \mathrm{M}$ sucrose containing $1 \mathrm{mM} \mathrm{MgCl}_{2}$. RNA polymerase I activity was assayed at high ionic strength in the presence of $\alpha$-amanitin according to Derenzini et al. (2005). The assay system, corresponding to a volume of $0.5 \mathrm{ml}$, contained: $0.1 \mathrm{M}$ of Tris-HCl buffer, $\mathrm{pH} 8.0,4 \mathrm{mM}$ of $\mathrm{MnCl}_{2}, 240$ $\mathrm{mM}\left(\mathrm{NH}_{4}\right)_{2} \mathrm{SO}_{4}, 0.9 \mathrm{mM}$ each of CTP, GTP and ATP, $18 \mathrm{mM}$ of nonradioactive UTP, $0.05 \mathrm{mM}$ of $\left[{ }^{3} \mathrm{H}\right] \mathrm{UTP}, 1 \mu \mathrm{g} / \mathrm{ml}$ of $\alpha$-amanitin. The $0.1 \mathrm{ml}$ of nuclear suspension used for the assay corresponded to a mean concentration of $50 \mu \mathrm{g}$ of DNA. Incubation was at $37^{\circ} \mathrm{C}$ for $10 \mathrm{~min}$. After incubation, an equal volume of $10 \%(\mathrm{w} / \mathrm{v})$ trichloroacetic acid was added and then the precipitate collected on glass-fiber filters (Whatman GF/C) which were washed several times with $5 \%$ trichloroacetic acid. Radioactivity was measured after the addition of scintillation fluid (Ready gel-Beckman).

\section{Silver staining for the proteins associated to the Nucleolar Organizer Regions}

Liver samples were fixed in $10 \%$ buffered formalin and paraffin wax embedded. The silver-staining procedure was conducted as previously described (Derenzini et al., 1993b). Briefly, histological sections were mounted on poly-L-lysine pretreated slides, dewaxed in xylene and ethanol, and progressively rehydrated. Slides were then removed from water to heat resistant plastic slide holders, fully immersed in $10 \mathrm{mM}$ sodium citrate buffer ( $\mathrm{pH}$ 6.0), and boiled in a commercially available pressure cooker at $120^{\circ} \mathrm{C}$ for 20 minutes. After cooling to room temperature, sections were stained with silver according to the "one step" method originally described by Ploton and co-workers (1986). Silver staining was carried out using a solution of one volume $2 \%$ gelatin in $1 \%$ aqueous formic acid and two volumes of $50 \%$ silver nitrate. The staining reaction was performed for 10 minutes at $37^{\circ} \mathrm{C}$. After washing, the sections were dehydrated and mounted in a synthetic medium.

\section{Electron microscopy}

Liver samples were fixed in the following solutions: a) $4 \%$ formaldehyde in 0.1 Sörensen buffer, $\mathrm{pH} 7.2$, for $1 \mathrm{~h}$, overnight rinsing in the buffer, $1 \%$ osmium tetroxide in the same buffer for $1 \mathrm{~h}$; b) $1 \%$ glutaraldehyde in 0.1 Sörensen buffer, $\mathrm{pH} \mathrm{7.2,} \mathrm{for} 10 \mathrm{~min}, 3: 1$ ethanol:acetic acid solution for $30 \mathrm{~min}$; c) $4 \%$ formaldehyde in 0.1 
Sörensen buffer, pH 7.2, for $1 \mathrm{~h}$, alone. The first fixation method was used for routine electron microscopy, the second for silver staining of the AgNOR proteins, the third for immuno-cytochemical detection of UBF. After fixation as in (a) the samples were dehydrated in ethanol and embedded in Epon. After fixation as in (b) the samples were rehydrated and treated with the silver-staining solution (Ploton et al., 1986) at $37^{\circ} \mathrm{C}$ for $10 \mathrm{~min}$. Samples were dehydrated in ethanol and embedded in Epon. After fixation as in (c) the samples were dehydrated in dimethylformamide and embedded in Lowicryl K4M.

Thin sections of samples from (a) were double stained with uranium and lead. Thin sections of samples from (b) were examined either without or after uranium and lead counterstaining. Thin sections of samples from (c) were treated over night at $4^{\circ} \mathrm{C}$ with anti-UBF(H-330) rabbit polyclonal antibodies (Santa Cruz Biotechnology, Inc., California, USA), diluted 1 to 100 , and then with goat anti-rabbit antibodies conjugated to $10 \mathrm{~nm}$ gold particles (British BioCell International, Cardiff, UK), for $1 \mathrm{~h}$ at room temperature; sections were also uranium counterstained.

a

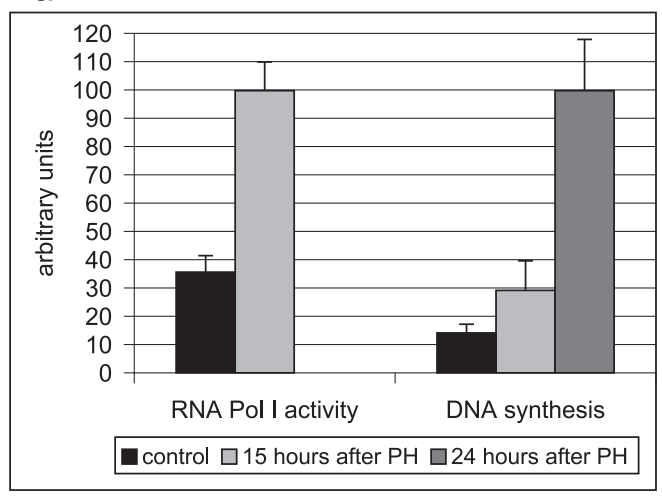

\section{Results}

There is evidence that after stimulation to proliferate by partial hepatectomy an increase of ribosome biogenesis rate occurs in the regenerating rat hepatocytes since the first hours after operation (Pession et al., 1991; Derenzini et al., 1995) whereas the rate of DNA synthesis does not increase for approximately 15 hours after operation (Steer, 1995). In agreement with these data, in the present experiments we found that the rRNA transcriptional activity, measured by the evaluation of the RNA polymerase I activity, was greatly increased in regenerating livers in comparison with sham-operated rat livers (Fig. 1a). Regarding the synthesis of DNA, it appeared to be very lightly increased at $15 \mathrm{~h}$ of regeneration in comparison with sham-operated rat livers and at difference of regenerating livers at $24 \mathrm{~h}$ after partial hepatectomy which were characterized by very high values of $\left[{ }^{3} \mathrm{H}\right]$ methyl-thymidine incorporation (Fig. 1a). Therefore, at $15 \mathrm{~h}$ after the partial hepatectomy, whatever the nucleolar changes might occur, these should be considered to be

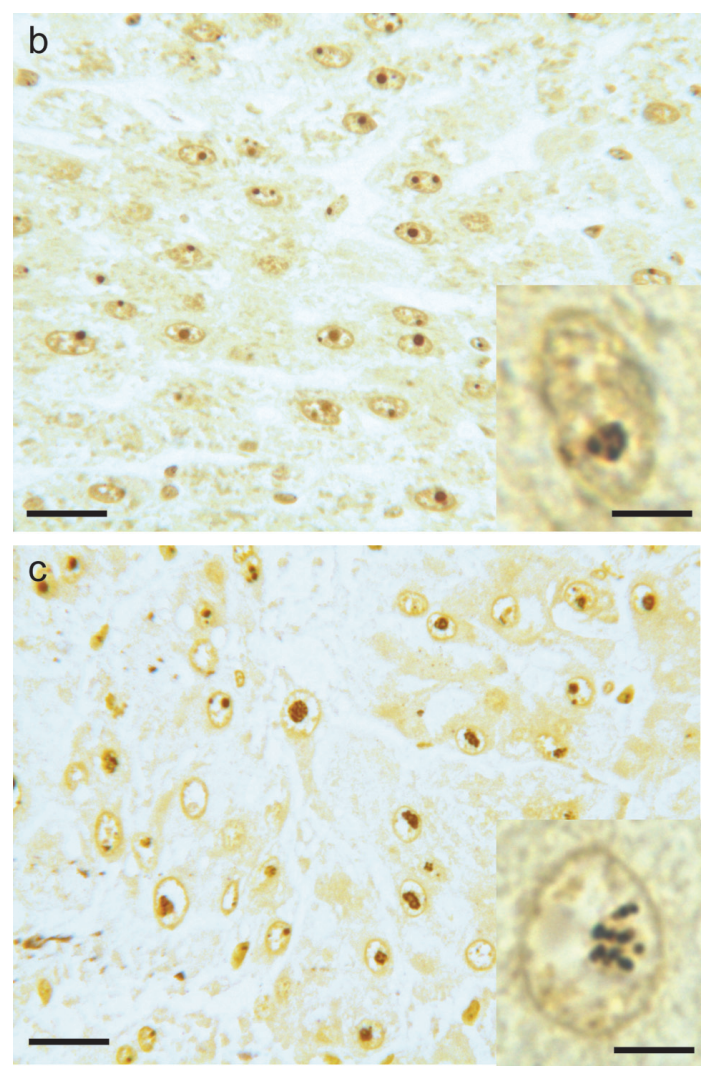

Fig. 1. (a) RNA polymerase I activity and DNA synthesis rate in control (sham operated) and partially hepatectomized rat liver. Three rats were used for each time point. Error bars indicate the standard deviation. (b) Histological section of liver from sham-operated rat, selectively stained for the AgNOR proteins. The nucleoli within the hepatocytes nuclei appear to be very intensely stained. Bar $=25 \mu \mathrm{m}$. In the insert, a hepatocytes nucleus is shown at higher magnification. In the nucleolus, three black-stained dots are visible. Bar $=5 \mu \mathrm{m}$. (c) Histological section of regenerating liver, stained as in (b). The silverstained nucleoli are larger than those of resting hepatocytes. Bar $=25 \mu \mathrm{m}$. In the insert, the enlarged nucleolus appears to be constituted by numerous black dots. $\mathrm{Bar}=5 \mu \mathrm{m}$ 

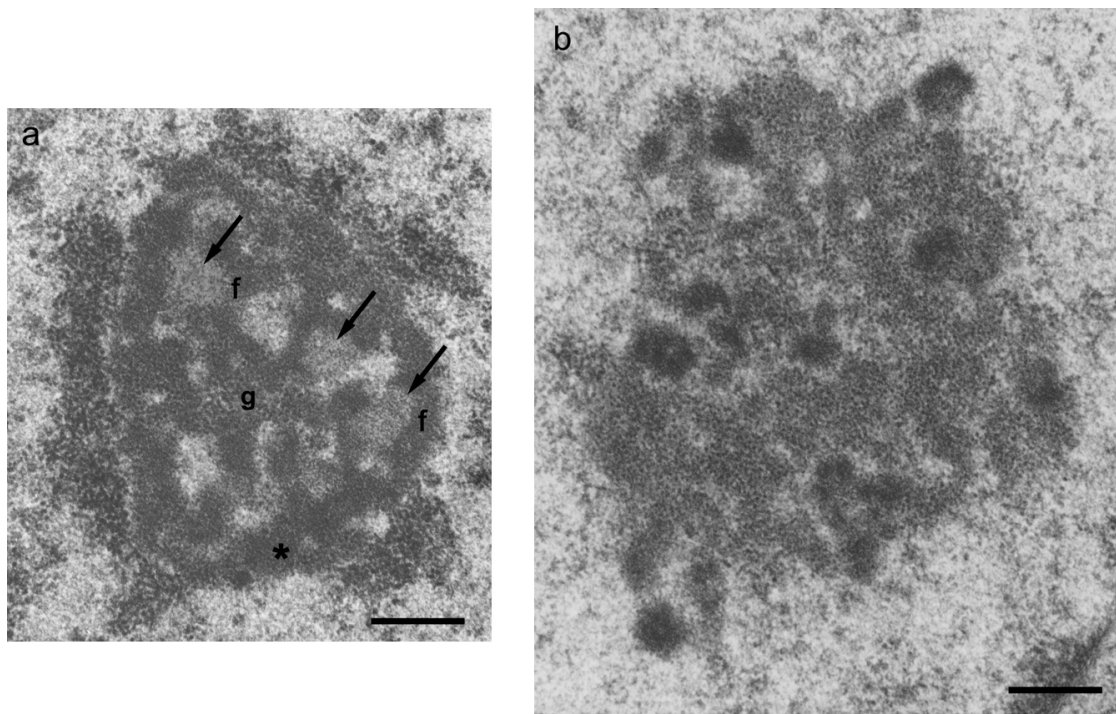

Fig. 2. (a) Thin section of resting rat hepatocyte. In the nucleolus, three FCs are clearly visible (arrows), with the intimately associated DFC (f). The FCs are small in size. A portion of the DFC appear to be not spatially related to the FCs (asterisk). g, granular component. Bar=0.15 $\mu \mathrm{m}$. (b) Thin section of regenerating rat hepatocyte. In the enlarged nucleolar body no structure referable to FCs is visible. The DFC is organized in small roundish tufts which are mainly distributed at the periphery of the nucleolus. $B a r=0.15 \mu \mathrm{m}$. Samples were aldehyde and osmium fixed and thin sections uranium and lead stained.

related to variation of RNA transcriptional activity and not due to an increased number of ribosome genes. For this reason, we have studied the nucleolar morphological changes in regenerating rat hepatocytes 15 hours after the partial hepatectomy.

The morphological changes of the hepatocyte nucleolus induced by partial hepatectomy were first investigated at light microscope level using the selective staining for the AgNOR proteins. There is evidence that this silver staining procedure allows the detection of active ribosomal genes in situ (Howell, 1982) by specifically staining a set of acidic proteins, the major being nucleolin (Roussel et al., 1992) which, in fact, is associated with the rDNA (Mongelard and Bouvet, 2007). During interphase, at electron microscopic level, this reaction is confined to the nucleolar fibrillar components (Hernandez-Verdun, 1986) where the silver grains co-localize with the rDNA, in a completely extended, open configuration (Derenzini et al., 2006). After silver staining of histological sections of liver from sham-operated rat, the hepatocyte nucleoli were black-stained (Fig. 1b) and, at high magnification, appeared to be composed by 3-4 dots (Fig. $1 \mathrm{~b}$, insert). At $15 \mathrm{~h}$ after the partial hepatectomy, the nucleoli were enlarged (Fig. 1c) in comparison with those in resting hepatocytes. At high magnification, the nucleoli of regenerating hepatocytes appeared to be constituted by black dots which were smaller in size and more numerous than those in nucleoli of resting hepatocytes (Fig. 1c, insert). These data were consistent with previous observations on the increased nucleolar size and AgNOR protein expression in regenerating rat hepatocytes (Pession et al., 1991; Sirri et al., 1995).
In thin sections stained with uranium and lead, the resting hepatocyte nucleolus showed a reticulate organization of the ribonucleoprotein components. The FCs were always present and easily recognizable as roundish structures characterized by a light electron opacity and surrounded by the DFC. We evaluated the diameter of the FCs and that of the FCs plus the intimately associated DFC. Fifty measurements were carried out and the values obtained appeared to be quite constant: $0.53 \pm 0.10 \mu \mathrm{m}$. In continuity with the thread-like structures of the DFC were the granules constituting the GC. At the periphery of the nucleolar ribonucleoprotein components compact chromatin clumps, perinucleolar chromatin, were visible (Fig. 2a). In thin sections of regenerating hepatocytes stained with uranium and lead, the nucleolar body was always enlarged and the ribonucleoprotein components exhibited a looser texture. In nucleoli of many hepatocytes the FCs were no longer present. The DFC appeared to be organized in numerous, small, roundish tufts, only in part embedded in the GC: in fact, they were frequently located at the periphery of the nucleolar body. The mean diameter of these tufts of DFC was $0.24 \pm 0.03 \mu \mathrm{m}$. The perinucleolar chromatin was no longer organized in compact clumps (Fig. 2b).

In Fig. 3a the nucleolus of a resting hepatocyte is shown, selectively stained for the AgNOR proteins, without any counterstaining. We observed that within the nucleolar body of the resting hepatocytes the silver staining gave rise to well separated, roundish deposits. The less stained central portion of these silver stained structures corresponds to the FCs while the more intensely stained peripheral portion corresponds to the DFC (Hernandez-Verdun, 1986). In nucleoli 

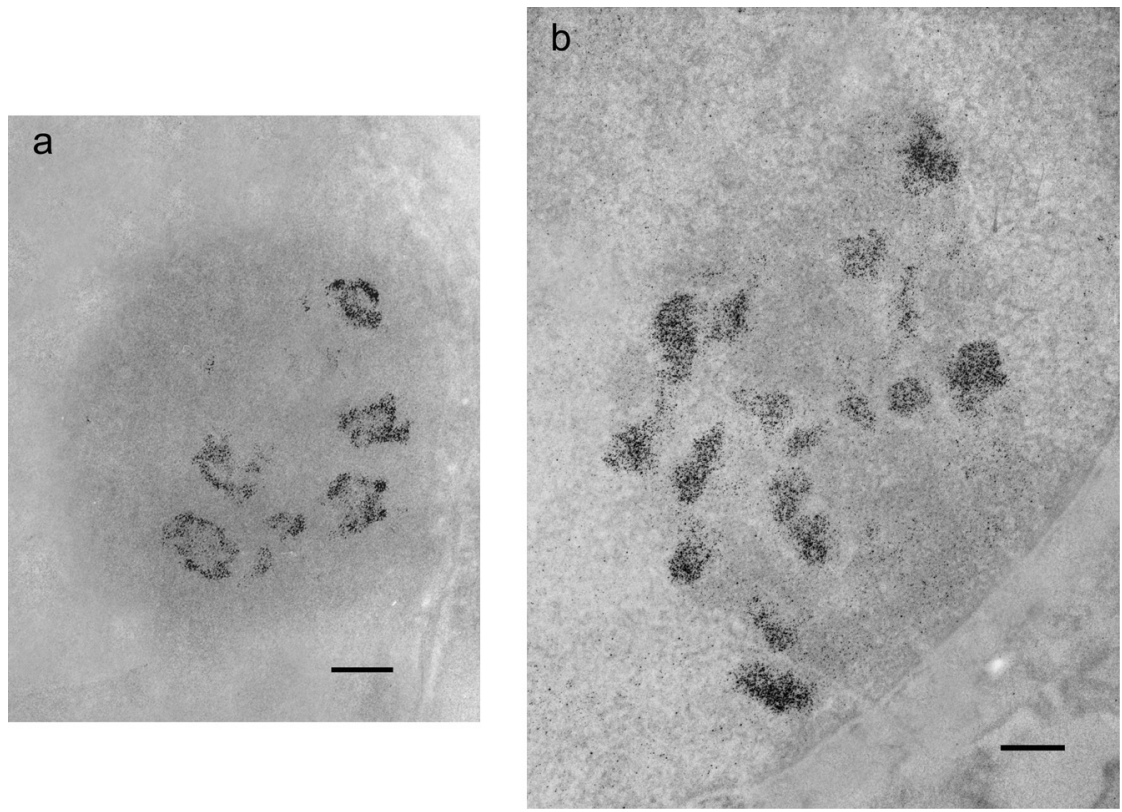

Fig. 3. Resting (a) and regenerating (b) rat hepatocyte selectively stained for the AgNOR proteins. In the nucleolus of the resting hepatocyte the silver deposits give rise to roundish structures with the same morphological pattern as the FCs plus the associated DFC. Note that the part corresponding to the FCs is lesser intensely stained than the part corresponding to the DFC. Bar $=0.1 \mu \mathrm{m}$. In the nucleolus of regenerating hepatocyte the silver grains are uniformly distributed in small roundish deposits. Bar $=0.1 \mu \mathrm{m}$. Thin sections were no counterstained.

of regenerating hepatocytes, the silver grains appeared to be uniformly distributed in numerous, small, roundish clumps scattered throughout the nucleolar body, without any difference between the inner and the outer portion regarding their concentration (Fig. 3b). The different distribution of the silver grains in the nucleolar fibrillar components was also clearly visible after uranium and lead counterstaining of silver-stained samples. In the resting hepatocyte nucleolus the silver grains were concentrated in the DFC, and to a lesser extent in the FCs (Fig. 4a); in the regenerating hepatocyte nucleolus the silver grains were exclusively located to the tufts of the DFC, no FC being any longer visible (Fig. 4b).

These results, taken together, indicated that in nucleoli of many regenerating hepatocytes the FCs were disappeared and strongly suggested that the tufts of DFC represent the sites of rRNA transcription. To demonstrate that this was actually the case we investigated the distribution of UBF in the nucleolar components at the electron microscope level, by the immuno-gold labeling procedure. UBF is a member of HMG (high mobility group) proteins and functions exclusively in RNA Polymerase I transcription. It is worth noting that in addition to the high affinity sites at the rDNA promoter, UBF is also enriched across the entire transcribed region of the rDNA repeat, maintaining ribosome chromatin in an extended, non-nucleosomal configuration (McStay and Grummt, 2008; Sanij and Hannan, 2009). Therefore, UBF should be exclusively localized in those nucleolar structures that contain transcriptionally active ribosome genes. In Fig. 5a and $\mathrm{b}$ a nucleolus of regenerating hepatocyte from Lowicryl-embedded liver sample is shown after treatment with anti-UBF antibodies revealed by gold-labelled secondary antibodies. Lowicryl embedding was necessary to successfully perform the gold-immunolabelling procedure. In Fig. 5a the tufts of the DFC were easily recognized; at higher magnification (Fig. 5b), the UBF immuno-gold labelling appeared to be mostly localized on the fibrillar tufts, thus demonstrating the presence of transcriptionally active ribosome genes within these structures.

\section{Discussion}

The present results showed that the most striking change of the nucleolar morphology which occurs in many regenerating rat hepatocytes 15 hours after partial hepatectomy was represented by the disappearance of the FCs. Also the DFC underwent structural changes, being no longer organized in cordon-like structures but in fact giving rise to numerous, small tuft-like structures mainly distributed at the periphery of the nucleolar body. These structures where uniformly stained by the silver-staining procedure specific for the AgNOR proteins and were the site where UBF was located, thus appearing to be the only ultrastructural component where active ribosomal genes were present in the nucleolus. Since at this time of regeneration the rRNA transcriptional 

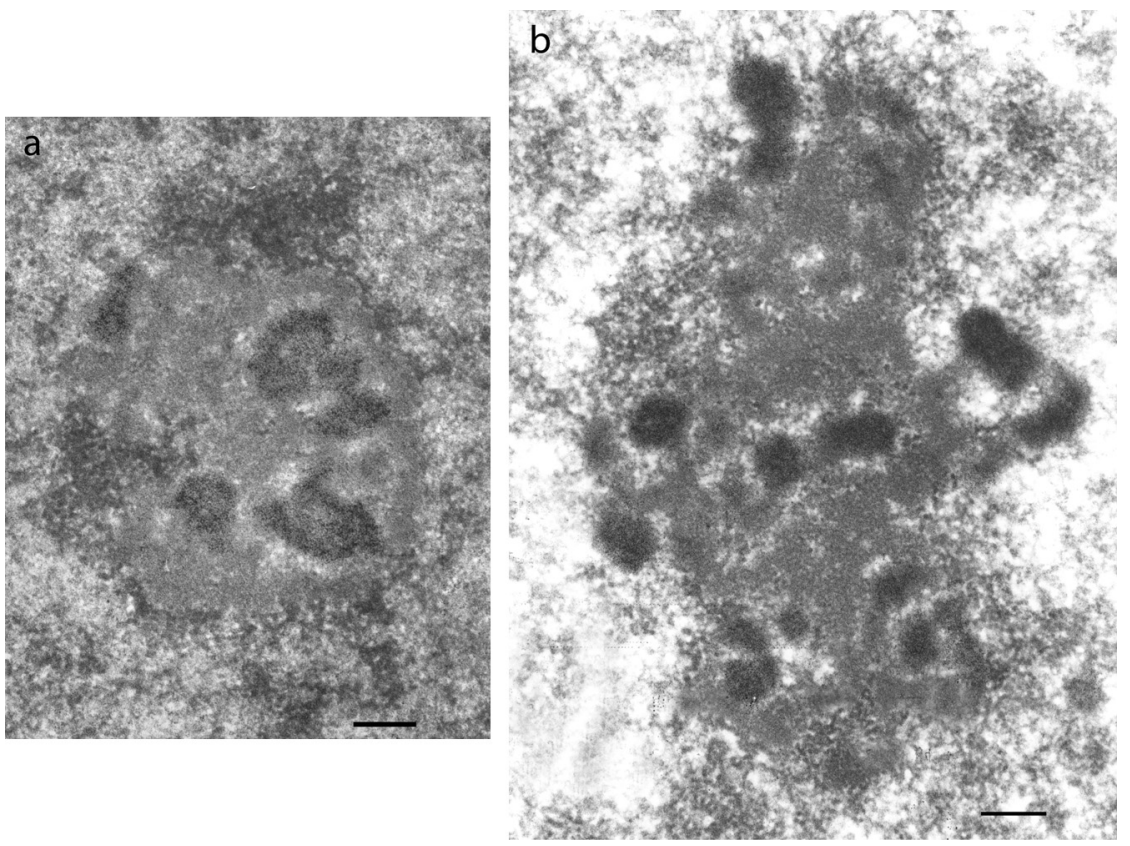

Fig. 4. Resting (a) and regenerating (b) rat hepatocyte stained for the AgNOR proteins and counterstained with uranium and lead. In the nucleolus of the resting hepatocyte, the silver deposits are located in the FCs and, to a larger extent, in the associated DFC. Bar $=0.1 \mu \mathrm{m}$. In the nucleolus of the regenerating hepatocyte the silver grains are exclusively located in the DFC. Bar $=0.1 \mu \mathrm{m}$.
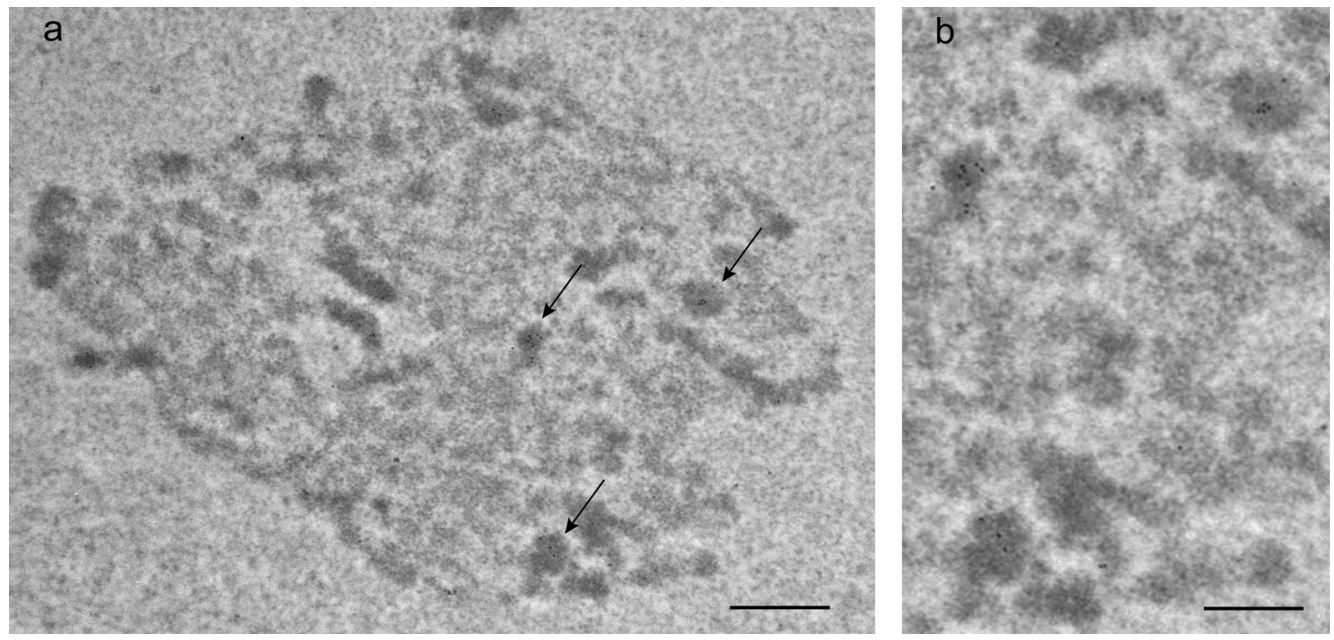

Fig. 5. Thin section of regenerating rat hepatocyte, immuno-gold labeled for UBF detection. Aldehyde fixation, Lowicryl embedding, uranium counterstaining. (a) A large nucleolus is shown in which tufts of DFC are clearly visible. Bar $=0.1 \mu \mathrm{m}$. Arrows indicate three DFC tufts which are shown at higher magnification in (b). These structures appear to be selectively enriched in gold granules (b). Bar $=0.05 \mu \mathrm{m}$.

activity was markedly increased in comparison with that of resting hepatocytes, while the synthesis of DNA was not yet significantly increased, these nucleolar changes can be reasonably ascribed to the increased ribosome biogenesis. We think that these results are of importance for the definition of the in situ structural-functional organization of the mammalian cell nucleolus.
A large series of studies has been carried out in order to define the precise location of rRNA transcription in these nucleolar components. Until 1984 it was generally accepted that the DFC represented the component where the transcriptionally active ribosome genes were located (Hadjiolov, 1985). However, at that date, findings were reported indicating the presence of RNA polymerase I in the FCs and not 
in other nucleolar components thus suggesting the FCs as the actual sites of transcription (Scheer and Rose, 1984). On the other hand, further observations indicated that all the substances necessary for the synthesis of rRNA were located both to the FCs and the DFC, thus opening a long lasting diatribe on the localization of the site of rRNA transcription within the nucleolar components, complicated by the fact that different experimental models and technical approaches were used. In the recent past years the different results obtained and the consequent different conclusions on the precise site of rRNA transcription have been reviewed and critically discussed mainly by Raska and co-workers (Raska, 2003, 2004; Raska et al., 2004, 2006a, b). As reported by these Authors, the greater part of evidence appeared to be consistent with the location of transcriptionally active ribosome genes either at the periphery of the FCs or within the DFC, even if, as stated by Raska et al. (2004), the problem might be exclusively semantic. In fact, once a given gene wherever located becomes fully active, it automatically becomes, through the process of transcription which generates ribonucleoprotein fibrils, a portion of DFC. The present results are quite consistent with this statement. Our data showed that in a substantial portion of regenerating rat hepatocytes, after stimulation of rRNA transcription by partial hepatectomy, the active ribosome genes, identified by the AgNOR silver-staining reaction and by UBF immuno-labeling, were exclusively located in the DFC, with the contemporary disappearance of the FCs. In other words, the increased demand for ribosome biogenesis occurring in regenerating hepatocytes appeared to induce a complete activation of the ribosome genes present within the FCs, which by producing the rRNA transcripts acquired the morphological aspect of the DFC. These findings did not allow to extrapolate that the $\mathrm{DFC}$, in cells different of regenerating hepatocytes, is the site, in its whole, of rRNA transcription. In fact, there is evidence that wherever observed to occur, rRNA transcription appears to be always confined to small foci and never uniformly distributed in the DFC (Hozak et al., 1994; Mosgoeller et al., 1998; Cheutin et al., 2002; Koberna et al., 2002) and that the dense fibrillar component is non-homogeneous in molecular composition (Mosgoeller et al., 2001). The identification of the DFC in its whole as the site of rRNA transcription was also not consistent with the present observation that in regenerating hepatocytes the DFC was lesser quantitatively represented than in resting hepatocytes, in which, despite a lower rRNA transcriptional activity, it was organized in cordon-like structures that occupy a great portion of the nucleolar body. The nucleolar changes above described were observed in a high portion of the hepatocytes of partial hepatectomized rats, even though hepatocytes were also present exhibiting nucleoli with a distribution of the ribonucleoprotein components similar to that of resting hepatocytes. This is consistent with the fact that after $2 / 3$ hepatectomy only a portion of hepatocytes enters the cell cycle during the first 24 hours of regeneration (Tamura et al., 1992).

A progressive reduction of the number of FCs together with a progressive reduction of their size has been described to occur in human circulating lymphocytes stimulated to proliferate by phytohemagglutinin (Hozak et al., 1989) until the maximum number of FCs approaches the ribosomal gene copy number of 200 at $48 \mathrm{~h}$ in culture (Ochs and Smetana, 1989). However, the disappearance of the FCs has been never described in PHA-stimulated human lymphocytes. A possible explanation for the different behavior between PHA-stimulated lymphocytes and regenerating hepatocytes may be represented by the different basal level or ribosome biogenesis present in the respective resting cells, being much higher in hepatocytes than in lymphocytes, where it is practically nil (Derenzini et al., 1983), as a consequence of their different size and function. In resting hepatocytes a much greater number of ribosome genes are engaged in transcription than in resting lymphocytes: therefore, the increased demand for ribosome biogenesis occurring when the cells enter the cell cycle might be only satisfied by the recruitment for transcription of the portion of the ribosome genes which, in the active configuration but not still actively transcribing, are present in the FCs, thus causing the disappearance of the FCs themselves. In the PHA-stimulated lymphocytes only a portion of these genes have to become transcriptionally active in order to produce a sufficient quantity of ribosomes to allow cell cycle progression.

It has been widely accepted that the FCs represent a constant feature of mammalian, and more extensively, of amniotes nucleoli. The FCs, together with the DFC and the GC give rise to the well known tripartite organization of the nucleolus. This tripartite structural-functional organization of mammalian cell nucleoli is not present in lower eukaryotes. A critical revision of the nucleolar structure in insects, amphibians, plants and yeast indicates that in these organisms only the DFC and the GC are present. It was proposed that during evolution the FCs made their appearance at the transition between the anamniotes and the amniotes as a consequence of a substantial increase of the rDNA intergenic regions (Thiry and Lafontaine, 2005). Therefore, the presence of FCs in mammalian cell nucleoli would reflect a different structure of the ribosomal genes independent of rRNA transcriptional activity. The present results on the morphological changes occurring in nucleoli of regenerating rat hepatocytes indicated that the presence of long rDNA intergenic regions is not necessarily responsible for the presence of FCs which, in fact, appears to be conditioned by the rate of rDNA transcriptional activity.

Acknowledgments. This work was supported by Roberto and Cornelia Pallotti's Legacy for Cancer Research, and MIUR (Italian Ministry of Education, University and Research: grants for Oriented Fundamental Research). 


\section{References}

Cheutin, T., O'Donohue, M.F., Beorchia, A., Vandelaer, M., Kaplan, H., Defever, B., Ploton, D., and Thiry, M. 2002. Three-dimensional organization of active rRNA genes within the nucleolus. J. Cell Sci., 115: 3297-3307.

Derenzini, M., Pession, A., Betts-Eusebi, C.M., and Novello, F. 1983. Relationship between the extended, nonnucleosomal intranucleolar chromatin in situ and ribosomal RNA synthesis. Exp. Cell Res., 145: 127-143.

Derenzini, M., Farabegoli, F., Pession, A., and Novello, F. 1987. Spatial redistribution of ribosomal chromatin in thefibrillar centres of human circulating lymphocytes after stimulation of transcription. Exp. Cell Res., 170: 31-41.

Derenzini, M., Farabegoli, F., and Trerè, D. 1993a. Localization of DNA in the fibrillar components of the nucleolus: a cytochemical and morphometric study. J. Histochem. Cytochem., 41: 829-836.

Derenzini, M., Trerè, D., Oliveri, F., David, E., Colombatto, P., Bonino, F., and Brunetto, M.R. 1993b. Is high AgNOR quantity in hepatocytes associated with increased risk of hepatocellular carcinoma in chronic liver disease? J. Clin. Pathol., 46: 727-729.

Derenzini, M., Sirri, V., Pession, A., Trerè, D., Roussel, P., Ochs, R.L., and Hernandez-Verdun, D. 1995. Quantitative changes of the two major AgNOR proteins, nucleolin and protein B23, related to stimulation of rDNA transcription. Exp. Cell Res., 219: 276-282.

Derenzini, M., Montanaro, L., Chillà, A., Tosti, E., Vici, M., Barbieri, S., Covoni, M., Mazzini, G., and Treré, D. 2005. Key role of the achievement of an appropriate ribosomal RNA complement for G1-S phase transition in H4-II-E-C3 rat hepatoma cells. J. Cell. Physiol., 202: 483491.

Derenzini, M., Pasquinelli, G., O’Donohue, M.F., Ploton, D., and Thiry, M. 2006. Structural and functional organization of ribosomal genes within the mammalian cell nucleolus. J. Histochem. Cytochem., 54: $131-145$.

Hadjiolov, A. 1985. The nucleolus and ribosome biogenesis. Cell Biol. Monographs, Vol. 12. Springer-Verlag, Wien and New York.

Hernandez-Verdun, D. 1986. Structural organization of the nucleolus in mammalian cells. Methods Achiev. Exp. Pathol., 12: 26-62.

Higgins, G.H. and Anderson, R.M. 1931. Experimental pathology of the liver. Restoration of the liver in the white rat following partial surgical removal. Arch. Pathol., 12: 186-202

Howell, W.M. 1982. Selective staining of nucleolus organiser regions (NORs). In The cell nucleus (H. Busch and L. Rothblum, eds.), Academic Press, New York, pp.89-143.

Hozak, P., Novak, J.T., and Smetana, K. 1989. Three-dimensional reconstructions of nucleolus-organizing regions in PHA-stimulated human lymphocytes. Biol. Cell, 66: 225-233.

Hozak, P., Cook, P.R., Schofer, C., Mosgoller, W., and Wachtler, F. 1994. Site of transcription of ribosomal RNA and intranucleolar structure in HeLa cells. J. Cell Sci., 107: 639-648.

Huang, S. 2002. Building an efficient factory: where is pre-rRNA synthesized in the nucleolus? J. Cell Biol., 157: 739-741.

Koberna, K., Malínsky, J., Pliss, A., Masata, M., Vecerová, J., Fialová, M., Bednár, J., and Raska, I. 2002. Ribosomal genes in focus: new transcripts label the dense fibrillar components and form clusters indicative of "Christmas trees" in situ. J. Cell Biol., 157: 743-748.

McStay, B. and Grummt, I. 2008. The epigenetics of rRNA genes: from molecular to chromosome biology. Annu. Rev. Cell Dev. Biol., 24: 131157.
Mongelard, F. and Bouvet, P. 2007. Nucleolin: a multiFACeTed protein. Trends Cell Biol., 17: 80-86.

Mosgoeller, W., Schöfer, C., Derenzini, M., Steiner, M., Maier, U., and Wachtler, F. 1993. Distribution of DNA in human Sertoli cell nucleoli. J. Histochem. Cytochem., 41: 1487-1493.

Mosgoeller, W., Schöfer, C., Wesierska-Gadek, J., Steiner, M., Muller, M., and Wachtler, F. 1998. Ribosomal gene transcription is organized in foci within nucleolar components. Histochem. Cell Biol., 109: 111-118.

Mosgoeller, W., Schöfer, C., Steiner, M., Sylvester, J.E., and Hozak, P. 2001. Arrangement of ribosomal genes in nucleolar domains revealed by detection of "Christmas tree" components. Histochem. Cell Biol., 116: 495-505.

Ochs, R.L. and Smetana, K. 1989. Fibrillar center distribution in nucleoli of PHA-stimulated human lymphocytes. Exp. Cell Res., 184: 552-557.

Pession, A., Farabegoli, F., Trere, D., Novello, F., Montanaro, L., Sperti, S., Rambelli, F., and Derenzini, M. 1991. The Ag-NOR proteins and transcription and duplication of ribosomal genes in mammalian cell nucleoli. Chromosoma, 100: 242-250.

Ploton, D., Menager, M., Jeannesson, P., Himber, G., Pigeon, F., and Adnet, J.J. 1986. Improvement in the staining and in the visualization of the argyrophilic proteins of the nucleolar organizer region at the optical level. Histochem. J., 18: 5-14.

Raska, I. 2003. Oldies but goldies: searching for Christmas trees within the nucleolar architecture. Trends Cell Biol., 13: 517-525.

Raska, I. 2004. Searching for active ribosomal genes. Prog. Mol. Subcell. Biol., 35: 23-56.

Raska, I., Koberna, K., Malinsky, J., Fidlerova, H., and Masata, M. 2004. The nucleolus and transcription of ribosomal genes. Biol. Cell, 96: 579594.

Raska, I., Shaw, P.J., and Cmarko, D. 2006a. New insights into nucleolar architecture and activity. Int. Rev. Cytol., 255: 177-235.

Raska, I., Shaw, P.J., and Cmarko, D. 2006b. Structure and function of the nucleolus in the spotlight. Curr. Opin. Cell Biol., 18: 325-334.

Roussel, P., Belenguer, P., Amalric, F., and Hernandez-Verdun, D. 1992. Nucleolin is an Ag-NOR protein; this property is determined by its amino-terminal domain independently of its phosphorylation state. Exp. Cell Res., 203: 259-269.

Sanij, E. and Hannan, R.D. 2009. The role of UBF in regulating the structure and dynamics of transcriptionally active rDNA chromatin. Epigenetics, 4: 374-382.

Scheer, U. and Rose, K.M. 1984. Localization of RNA polymerase I in interphase cells and mitotic chromosomes by light and electron microscopic immunocytochemistry. Proc. Natl. Acad. Sci. USA, 8: 14311435.

Scheer, U. and Hock, R. 1999. Structure and function of the nucleolus. Curr. Opin. Cell Biol., 11: 385-390.

Sirri, V., Roussel, P., Trerè, D., Derenzini, M., and Hernandez-Verdun, D. 1995. Amount variability of total and individual Ag-NOR proteins in cells stimulated to proliferate. J. Histochem. Cytochem., 43: 887-893.

Steer, C.J. 1995. Liver regeneration. FASEB J., 9: 1396-1400.

Tamura, J., Tanaka, J., Fujita, K., Yoshida, M., Kasamatsu, T., Arii, S., and Tobe, T. 1992. Cell kinetics of regenerating liver after $70 \%$ hepatectomy in rats-2-color flow cytometric analysis. HPB Surg., 5: 103-114.

Thiry, M. and Lafontaine, D.L. 2005. Birth of a nucleolus: the evolution of nucleolar compartments. Trends Cell Biol., 15: 194-199.

(Received for publication, September 24, 2010, accepted, January 26, 2011 and published online, February 9, 2011) 